\title{
Maternal insulin-like growth factor binding protein-1, body mass index, and fetal growth
}

\author{
Robert P Holmes, J M P Holly, Peter W Soothill
}

\begin{abstract}
Aim-To examine the hypothesis that the maternal insulin-like growth factor system may constrain fetal growth. Methods-A prospective observational study of maternal serum insulin-like growth factor binding protein-1 (IGFBP-1) and fetal growth was undertaken in neonates with birthweights below the 5 th centile. They had been classified either as having fetal growth restriction (FGR) due to placental dysfunction (increased umbilical artery Doppler pulsatility index (PI); $n=25$ ) or as being small for gestational age (SGA; normal umbilical artery PI, growth velocity and amniotic fluid; $\mathbf{n}=27$ ). Eighty nine controls had normal birthweights (5th-95th centile), umbilical artery PI, growth velocity, and amniotic fluid. IGFBP-1 was measured by radioimmunoassay.

Results-Among the controls, there was no significant correlation between IGFBP-1 and birthweight after allowing for body mass index (BMI). Maternal BMI was high in FGR and after adjusting for this, IGFBP-1 was increased $(109 \mathrm{ng} / \mathrm{ml})$ compared with SGA babies $(69 \mathrm{ng} / \mathrm{ml})$ and controls $(57 \mathrm{ng} / \mathrm{ml})$ and correlated with the umbilical artery PI.

Conclusions-Maternal IGFBP-1 is probably not part of normal placental function. Its increase in FGR could be the cause or consequence of impaired placental perfusion, but high IGFBP-1 concentrations might further reduce the availability of maternal IGF-I to the placenta. This could worsen placental function and so adversely affect fetal growth.
\end{abstract}

(Arch Dis Child Fetal Neonatal Ed 2000;82:F113-F117)

Keywords: insulin-like growth factor binding protein-1; growth restriction; umbilical artery; Doppler pulsatility index

Fetal growth is controlled by genetic, environmental, and nutritional factors. The nongenetic elements become increasingly important in the second half of pregnancy and contribute to the natural phenomenon of maternal constraint on the size of the baby, so overriding paternal genetic influences. Conversely, environmental factors might lead to fetal overgrowth, the most common example being maternal diabetes mellitus. Although the insulin-like growth factor (IGF) system mediates growth in response to nutritional signals in the fetus, the part played by the maternal IGF system is less well established.

IGF-I is an important growth factor and hormone which regulates protein turnover as well as having potent mitogenic and differentiating effects on most cell types. In mothers whose pregnancies incur fetal growth restriction (FGR) IGF-I concentrations are greatly reduced. ${ }^{1}$ In mice, increasing maternal IGF-I concentrations result in a heavier litter size and prevent the reduction in the average fetal weight which normally occurs with increasing litter number. ${ }^{2}$ Furthermore, in sheep, maternal IGF-I infusion results in increased fetal glucose concentrations and placental amino acid uptake, ${ }^{3}$ presumably via effects on placental function and transfer. These observations suggest that IGF-I might override the normal process of maternal constraint.

There are at least seven IGF binding proteins (IGFBP) that act not only as carrier proteins but also as regulators by controlling bioavailability of IGF-I to tissues. IGFBP-1 (synonymous with placental protein 12 and human pregnancy-associated endometrial $\alpha-1$ globulin) has a molecular weight of 25 kiloDaltons and binds IGF-I to form a 34 kiloDalton complex. This complex can cross intact endothelium and so may be involved in delivery of IGF-I to the tissues. Although in theory this could enhance IGF-I availability, IGFBP-1 inhibits IGF-I action in most in vitro systems and in blood.

Several observations suggest that maternal IGFBP-1 is important in pregnancy. Concentrations rise rapidly in the first 12 weeks of pregnancy $^{4}$ and remain high until delivery. ${ }^{5}$ The main source of this increased production is likely to be the decidualised endometrium. In the absence of pregnancy a single phosphorylated form of IGFBP-1 is secreted by the liver; in pregnancy less phosphorylated and nonphosphorylated forms with lower binding affinities are present, probably as a result of the action of a phosphatase secreted by decidua. Furthermore, increased IGFBP-1 concentrations have been reported in preterm delivery, ${ }^{6}$ pre-eclampsia, ${ }^{7}$ and gestational diabetes mellitus. $^{8}$ 
A significant correlation between maternal IGFBP-1 and birthweight has been reported by some groups ${ }^{589}$ but not all. ${ }^{10}$ Studies of unselected whole populations may detect correlations absent in studies of selected normal pregnancies because cases with pathology are included. Indeed, Baldwin et $a l^{9}$ observed low IGFBP-1 in diabetes, and Larsen et $a l^{11}$ and Langford $e t a l^{12}$ showed high concentrations in FGR. Larsen et $a l^{11}$ found no correlation between IGFBP-1 and maternal weight but a negative association was reported by Baldwin et $a l^{9}$ and Hills et al. ${ }^{5}$ IGFBP-1 is closely involved in carbohydrate metabolism, ${ }^{13}$ being regulated by insulin, ${ }^{14}$ and as maternal size is also an important predictor of birthweight, ${ }^{15}$ the confounding effect of maternal size on the relation between IGFBP-1 and birthweight warranted further consideration. A pilot study of highly selected pregnancies presenting for prenatal diagnosis by cordocentesis who were recruited to assess changes in fetal blood suggested that maternal IGFBP-1 was increased in FGR. ${ }^{1}$ However, as maternal results were not a primary end point, this retrospective study of very unusual pregnancies did not explore the relation between maternal IGFBP-1, body mass index (BMI), and fetal growth.

To clarify these issues we undertook a longitudinal study of new groups of women with small and appropriately grown fetuses from 24 weeks to term. No data from the previous publication were included in this study. These pregnancies were followed prospectively until delivery with comprehensive assessment using ultrasound biometry and umbilical artery Doppler velocimetry. The pregnancies with small for gestational age (SGA) fetuses were further classified into two groups: those with normal placental function, growing to their genetic potential (SGA), and those with fetal growth restriction (FGR) due to placental dysfunction.

\section{Methods}

This was a prospective, observational study of 75 women, each of whom had a singleton fetus with an ultrasonographically defined abdominal circumference (AC) measurement smaller than -2 standard deviations (SD) for gestational age in the second half of pregnancy (Harris Birthright Trust Database, Viewpoint, Bildverarbeatung, Gmb, Gilching, Germany) and no suspicion of fetal abnormality. They were recruited after approval by the local research ethics committee and written patient consent. One hundred and nine women who had uncomplicated singleton pregnancies with normal AC ( -2 to $+2 \mathrm{SD})$ were also recruited as controls. All pregnancies had confirmation of gestational age by ultrasound scan in the first half of pregnancy. Maternal BMI (weight in $\mathrm{kg} /$ height in $\mathrm{m}^{2}$ ) was recorded using data obtained at the booking antenatal appointment early in the second trimester.

Each fetus was scanned every two weeks until delivery with measurement of the AC, head circumference, biparietal diameter and femur length (ATL Ultramark 9, Bothell, Washington, USA or Acuson XP-10, Moun- tain View, California, USA). Fetal anatomy was inspected to exclude structural anomalies and markers of karyotypic abnormality or infection, and invasive testing was performed subsequently, as medically indicated. Placental function was assessed by umbilical artery Doppler velocimetry studies and measurement of the amniotic fluid index (AFI). At each visit, $2 \mathrm{ml}$ of maternal venous blood were drawn into a fluoride tube for plasma random glucose measurement and $16 \mathrm{ml}$ into two tubes without heparin. This was allowed to clot, centrifuged at $4000 \mathrm{rpm}$ for five minutes, and the serum stored at $-24^{\circ} \mathrm{C}$. IGFBP-1 concentrations undergo marked diurnal variation but are relatively stable between 10:00 and 16:00 hours in late pregnancy ${ }^{16}$ and so non-fasting samples were taken within these hours.

Classification of cases and controls was made after delivery. Criteria for exclusion of potential cases were a birthweight greater than the 5 th centile for gestational age $(-1.645 \mathrm{SD})$ $(\mathrm{n}=18)$ or evidence of structural $(\mathrm{n}=0)$, chromosomal $(n=2)$, or infectious congenital anomalies $(n=1)$ at birth. Remaining cases were then separated on the basis of the last umbilical artery pulsatility index (PI) before delivery into two subgroups: FGR (due to placental dysfunction) and SGA (normal small). The umbilical artery PI was expressed as multiples of SD of the normal mean for gestational age because it changes with gestational age, and a measurement exceeding $+2 \mathrm{SD}$ defined FGR. Doppler was used as the sole criterion for classifying FGR because it is the best clinical test of placental function ${ }^{17}$ and predicts outcome better than amniotic fluid assessment or cardiotocography. ${ }^{18}$ AFI measurement is more subjective and harder to reproduce than Doppler so an AFI less than the 5th centile was not used to define FGR in pregnancies with a normal umbilical artery PI. Nor were these pregnancies $(n=2)$ included in the SGA group because a severe reduction in amniotic fluid volume in the absence of fetal renal abnormality or ruptured membranes can be an indicator of early placental dysfunction. All SGA cases had an umbilical artery PI between -2 and +2 $\mathrm{SD}$ of the normal mean for gestational age and an AFI $>5 \mathrm{~cm}$. Fetuses defined as SGA by these criteria have a normal pregnancy outcome. ${ }^{19}$ The criteria for FGR and SGA were defined before the study with the aim of minimising mixing of the groups and so the final study groups comprised 25 FGR cases and 27 SGA cases.

Criteria for exclusion of potential controls were a birthweight less than the 5 th centile for gestational age $(-1.645 \mathrm{SD})(\mathrm{n}=7)$ or greater than the 95th centile (+1.645 SD) $(n=3)$, the development of gestational hypertension $(\mathrm{n}=$ 3 ) or diabetes $(n=1)$, a reduced AFI at term ( $n$ $=4)$ or reduced growth velocity at term $(n=2)$. No control developed an abnormal umbilical artery PI. The final number of controls for analysis was 89 . The case and control criteria were agreed before the study, with the aim of preventing misclassification and all exclusions were made before any serum samples were analysed. 
The last maternal serum sample obtained before labour from the 52 FGR and SGA cases was analysed. A cross sectional normal range with an even gestational age spread of results from 24 to 42 weeks was constructed by selecting a single sample from each of the 89 controls (before any laboratory work) stratifying by gestational age.

IGFBP-1 was assayed using a specific radioimmunoassay. ${ }^{4} \quad$ Recombinant human IGFBP-1 was kindly supplied by Synergen (Boulder, Colorado, USA) and used for both standards and $\mathrm{I}^{125}$ tracer. A polyclonal antiserum raised in sheep against purified human IGFBP-1 (S515) was used. Phosphate buffered saline assay $(0.25 \mathrm{M}$ with $28.4 \mathrm{~g} / 1$ disodium hydrogen orthophosphate, $6.81 \mathrm{~g} / 1$ potassium dihydrogen orthophosphate, $48.83 \mathrm{~g} / 1$ sodium chloride, $0.35 \mathrm{~g} / 1$ sodium azide adjusted to $\mathrm{pH}$ 7.5 and diluted five times in water and 10\% horse serum) was used to dilute the IGFBP-1 antibody which had a final dilution in the assay of 1 in 700 000. The standard curve had a range of $1-200 \mathrm{ng} / \mathrm{ml}$. The intra-assay coefficients of variation using the same assay, but at a wider range (1-400 $\mathrm{ng} / \mathrm{ml})$, were $10.3 \%$ and $9.1 \%$ at $9 \mathrm{ng} / \mathrm{ml}$ and $353 \mathrm{ng} / \mathrm{ml}$, respectively, and the interassay coefficients of variation were $10.6 \%$ and $7.0 \%$ at $106 \mathrm{ng} / \mathrm{ml}$ and $253 \mathrm{ng} / \mathrm{ml}$, respectively. The limit of detection of the assay was $6 \mathrm{ng} / \mathrm{ml}$.

Normality of distribution was assessed by the Shapiro-Wilk test after $\log _{10}$ transformation if required. IGFBP-1 was only normally distributed after this transformation so all subsequent analysis was on $\log _{10}$ IGFBP-1. Maternal characteristics and serum IGFBP-1 were compared between the groups using one way analysis of variance followed by Dunnett's test. Both birthweight and umbilical artery PI change with gestational age in control pregnancies and so results were expressed as multiples of SD of the normal mean for gestational age (z score). In control pregnancies, birthweight $\mathrm{SD}$, umbilical artery PI SD, maternal BMI, weight and height were tested for correlation with $\log _{10}$ transformed IGFBP-1 using linear regression analysis. Multiple regression analysis was used to adjust for the confounding effect of BMI on the relation between log. IGFBP-1 and birthweight $\mathrm{SD}$ and on the differences in log. IGFBP-1 concentrations in the FGR, SGA, and control groups using two dummy variables.

Table 1 Maternal characteristics in pregnancies with normally grown, SGA, and FGR fetuses

\begin{tabular}{|c|c|c|c|}
\hline & Controls $(n=89)$ & $S G A(n=27)$ & $F G R(n=25)$ \\
\hline $\begin{array}{l}\text { Age (years) } \\
\text { Mean (SD) }\end{array}$ & $29.3(5.5)$ & $\star 24.8(5.2)$ & $30.2(6.3)$ \\
\hline $\begin{array}{l}\text { Body mass index } \\
\text { Mean (SD) }\end{array}$ & $22.8(3.0)$ & $22.5(4.4)$ & $\star 26.9(6.1)$ \\
\hline $\begin{array}{l}\text { Height }(\mathrm{cm}) \\
\text { Mean }(\mathrm{SD})\end{array}$ & $161.8(18.5)$ & $162.5(6.2)$ & $160.6(9.4)$ \\
\hline $\begin{array}{l}\text { Random plasma glucose }(\mathrm{mmol} / \mathrm{l}) \\
\text { Mean (SD) }\end{array}$ & $4.8(0.9)$ & $4.7(1.2)$ & $5.0(0.9)$ \\
\hline
\end{tabular}

SGA, small for gestational age; FGR, fetal growth restriction.

* Significantly different from controls by one way analysis of variance followed by Dunnett's test $(\mathrm{p}<0.05)$

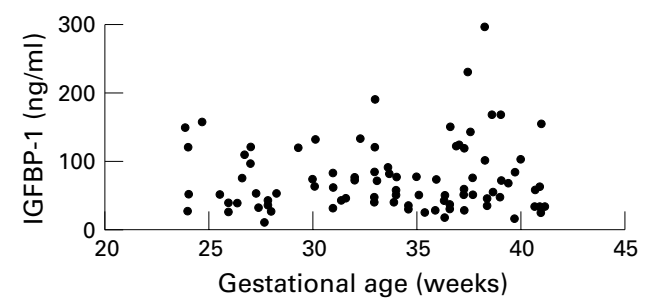

Figure 1 Maternal serum IGFBP-1 ( $\mathrm{ng} / \mathrm{ml})$ in controls plotted against gestational age in weeks. There was no significant change in IGFBP-1 with advancing gestational age $(r=0.15, n=89)$.

\section{Results}

Maternal characteristics in the control, SGA, and FGR groups are shown in table 1. The mean age of SGA mothers (24.8 years) was significantly lower than that of control mothers (29.3 years, $\mathrm{p}<0.05)$, but the age of FGR mothers was similar to that of the controls (30.2 years). The mean maternal BMI in FGR $\left(26.9 \mathrm{~kg} / \mathrm{m}^{2}\right)$ was significantly higher than that of controls $\left(22.8 \mathrm{~kg} / \mathrm{m}^{2}, \mathrm{p}<0.05\right)$ whereas the mean maternal BMI in SGA was not (22.5 $\left.\mathrm{kg} / \mathrm{m}^{2}\right)$. The mean weight of FGR mothers $(67.9 \mathrm{~kg})$ was also significantly higher than that of the controls $(60.6 \mathrm{~kg}, \mathrm{p}<0.05)$ while the mean weight of SGA mothers was similar (59.3 $\mathrm{kg}$ ). Height and random plasma glucose were similar in all groups.

The IGFBP-1 concentrations in control pregnancies by gestational age are shown in fig 1. After $\log _{10}$ transformation, these data were normally distributed and there was no change in maternal serum log. IGFBP-1 with advancing gestational age $(r=0.15, \mathrm{n}=89)$. The mean control IGFBP-1 concentration was 57 $\mathrm{ng} / \mathrm{ml}$. There was a significant negative correlation between control log. IGFBP-1 and birthweight SD $(r=-0.22, \mathrm{n}=89, \mathrm{p}<0.04)$ and maternal BMI $(r=-0.30, \mathrm{n}=89, \mathrm{p}<$ 0.005), but not between control log. IGFBP-1 and maternal weight or height. Therefore, it was essential to remove the effect of BMI on IGFBP-1 in all subsequent analyses.

After adjusting for the effect of maternal BMI, using multiple regression analysis, there was no independent significant correlation between control log. IGFBP-1 and birthweight SD. The correlation between control log. IGFBP-1 and maternal BMI remained significant after removing the effect of birthweight SD $(p=0.01)$.

After adjusting for maternal BMI, the mean IGFBP-1 in the FGR group (109 $\mathrm{ng} / \mathrm{ml})$ was increased compared with that in the control group $(57 \mathrm{ng} / \mathrm{ml}, \mathrm{p}=0.003)$ but the mean concentration in SGA cases $(69 \mathrm{ng} / \mathrm{ml})$ was similar to that of controls. In the FGR group, but not the SGA group, there was a significant negative correlation between log. IGFBP-1 and birthweight SD score $(r=-0.47, \mathrm{n}=27, \mathrm{p}<0.04)$ which was no longer significant after allowing for the effect of BMI. Log. IGFBP-1 correlated with the severity of placental dysfunction as indicated by umbilical artery PI $(r=0.26, \mathrm{n}=$ $141, \mathrm{p}=0.002)$. 


\section{Discussion}

Within normal control pregnancies we found a weak negative correlation between IGFBP-1 and birthweight similar to that reported by Hills et $a l,{ }^{5}$ but we have shown that this was explained by the confounding correlation of IGFBP-1 with maternal BMI. This indicates that the link between IGFBP-1 and birthweight in normal pregnancies relates to nutrition, carbohydrate metabolism, and adiposity especially as maternal height (a reflection of genetic growth potential) did not correlate with IGFBP-1 in our study. IGFBP-1 is closely involved in acute glucose regulation ${ }^{13}$ as both are controlled by insulin. ${ }^{20}$ Maternal IGFBP-1 is low in gestational diabetes, ${ }^{9}$ and insulin sensitivity in diabetics is an important independent predictor of birthweight. ${ }^{21}$ Women with the polycystic ovarian syndrome have low IGFBP-1 concentrations which are related to insulin sensitivity even after controlling for increased BMI. ${ }^{22}$ These observations suggest that the explanation for our finding of an association between IGFBP-1 and birthweight confounded by BMI might be due to insulin sensitivity.

The absence of a relation between birthweight and maternal IGFBP-1 in the control pregnancies, after adjusting for $\mathrm{BMI}$, is further emphasised by the finding that IGFBP-1 was unchanged in the mothers of SGA cases. This was despite our rigorous definition of SGA (below the 5th centile or $-1.645 \mathrm{SD}$ of the control mean for gestational age) which resulted in a mean birthweight SD for the group of $-2.01 \mathrm{SD}$, much smaller than would have been attained by using the conventional SGA definition of birthweight below the 10th centile (-1.28 SD). However, the maternal height, weight, BMI and random blood sugar were similar to those of controls and there was no increase in adverse perinatal outcome, so we consider these pregnancies to be normal, the fetuses having grown to their genetic potential. We would anticipate normal nutrition and glucose metabolism in these women.

Our findings of increased maternal IGFBP-1 concentrations, after adjusting for $\mathrm{BMI}$ in pregnancies complicated by FGR but not SGA, are consistent with previous observations. ${ }^{1112}$ In the FGR but not the SGA group there was a significant correlation between IGFBP-1 and birthweight SD. IGFBP-1 inhibits the actions of IGF-I in most systems studied and so the consequence of high IGFBP-1 in FGR may be to further reduce availability of the already low maternal IGF-I concentrations in these cases. ${ }^{23}$ In animal studies placental nutrient transfer was increased when maternal IGF-I concentrations were raised, ${ }^{2-3}$ so very low unbound IGF-I in FGR could be detrimental to the already compromised placental function. High maternal IGFBP-1 in FGR might also protect the fetus because glucose transfer to an already hypoxic fetus may cause lactic acid accumulation and acidosis. ${ }^{24}$ However, the high IGFBP-1 is unlikely to be an adaptive protective mechanism because a correlation between eventual birthweight and IGFBP-1 has been reported as early as 11

\section{Key messages}

- Maternal insulin-like growth factor-1 (IGFBP-1) does not correlate with birthweight in normal pregnancy but concentrations are increased in fetal growth restriction (FGR)

- Maternal body mass index is an important confounder when assessing the relation between maternal IGFBP-1 and fetal growth

- Increased maternal IGFBP-1 in FGR may further reduce availability to the placenta of already low concentrations of IGFBP-1

- Normal maternal IGFBP-1 concentrations in small for gestational age pregnancies indicates the use of umbilical artery Doppler to assess placental function when fetal size is $<5$ th centile for gestational age

weeks of gestation, ${ }^{5}$ a stage in pregnancy when the metabolic demands of the fetus are still low.

High maternal IGFBP-1 in FGR is unlikely to be related to maternal carbohydrate metabolism because these women were not malnourished and there was no evidence of altered glucose tolerance. Indeed, their median BMI was significantly higher than that of the controls so low IGFBP-1 concentrations would have been anticipated. The high BMI we observed in FGR supports the hypothesis that small maternal stature is not a risk factor for FGR and that most small fetuses of low BMI women are normally grown to their genetic potential and are not a consequence of placental dysfunction.

Our study showed a correlation between IGFBP-1 and worsening placental function, assessed by abnormal blood velocity waveforms in the umbilical artery. It is well established that these Doppler changes indicate characteristic pathological changes in the placenta. ${ }^{25}$ It therefore seems likely that high maternal IGFBP-1 concentrations in FGR may be a consequence of abnormal placental development. This is supported by the observation that IGFBP-1 is high in pre-eclampsia, especially if associated with proteinuria. ${ }^{7}$ In such cases abnormalities of the uteroplacental circulatory may be already present in the early second trimester. It has been suggested that hypoxia itself might increase gene expression for IGFBP $-1,{ }^{26}$ so changes within the decidua as a result of hypoxia due to poor development of maternal spiral artery vasculature could induce IGFBP-1. This may prevent trophoblast invasion continuing beyond that which could be supported by the decidua. For these reasons the high maternal IGFBP-1 concentrations which we observed in FGR in the second half of pregnancy could be the consequence of persisting placental hypoxia and would explain the correlation between IGFBP-1 and umbilical artery Doppler. The wide variation in concentrations found in our FGR cases suggest that IGFBP-1 is unlikely to be a clinically useful biochemical marker of placental dysfunction. Whether standardised fasting 
concentrations, or expression of the data as a ratio to IGF-I or IGFBP-1 response to a glucose challenge, would have a better specificity and sensitivity remains to be explored.

The high concentrations could even be causal because it has been suggested that IGFBP-1 synthesised in the decidua from early in pregnancy may inhibit trophoblast invasion. ${ }^{27}$ The observation that IGFBP-1 inhibits the mitogenic effects of IGFs in endometrial stromal cells ${ }^{28}$ supports an inhibitory role for IGFBP-1 in early placental development. IGFBP- 1 mRNA is expressed in the glands and stromal cells of the decidua rather than the placenta, ${ }^{29}$ suggesting a role in communication at the feto-maternal interface, but a direct inhibitory growth effect on the placenta itself is possible due to the close proximity of the decidua to the trophoblast.

Our understanding of the maternal IGF system is still far from complete but our data support the hypothesis that the system is related to placental dysfunction and maternal metabolic adaptations to pregnancy.

We thank Dr Linda Hunt, Department of Child Health at the Royal Hospital for Sick Children, Bristol for her statistical advice.

1 Holmes R, Montemagno R, Jones J, Preece M, Rodeck C, Soothill P. Fetal and maternal plasma levels of insulin-like
growth factors and binding proteins in pregnancies with appropriately grown or growth retarded fetuses. Early Hum Dev 1997;49:7-17.

2 Morel PC, Blair HT, Ormsby JE, Breier BH, McCutcheon $\mathrm{SN}$, Gluckman PD. Influence of fetal and maternal genotype for circulating insulin-like growth factor-I on fetal type for circulating insulin-like growth factor-I
growth in mice. $\mathcal{F}$ Reprod Fertil 1994;101:9-14.

3 Liu L, Harding JE, Evans PC, Gluckman PD. Maternal insulin-like growth factor-I infusion alters feto-placental carbohydrate and protein metabolism in pregnant sheep. Endocrinology 1994;135:895-900.

4 Wang HS, Perry LA, Kanisius J, Iles RK, Holly JMP, Chard T. Purification and assay of insulin-like growth factorbinding protein-1: measurement of circulating levels throughout pregnancy. F Endocrinol 1991;128:161-8.

5 Hills FA, English J, Chard T. Circulating levels of IGF-1 and IGF-binding protein-1 throughout pregnancy: relation to birthweight and maternal weight. $\mathcal{F}$ Endocrino 1996;148:303-9.

6 Wang HS, Lee CL, Chard T. Levels of insulin-like growth factor-I and insulin-like growth factor binding protein-1 in pregnancy with preterm delivery. Br f Obstet Gynaecol pregnancy with

7 Iino K, Sjoberg J, Seppala M. Elevated circulating levels of a decidual protein, placental protein 12 , in pre-eclampsia. decidual protein, placental prote

8 Hall K, Hansson U, Lundin G, Luthman M, Persson B, Povoa G et al. Serum levels of somatomedins and somatomedin-binding protein in pregnant women with type I or gestational diabetes and their infants. $f$ Clin Endocrinol Metab 1986;63:1300-6.

9 Baldwin S, Chung T, Rogers M, Chard T, Wang HS. Insulin-like growth factor binding protein-1, glucose tolerance and fetal growth in human pregnancy. 7 Endocrinol 1993;136:319-25.

10 Whittaker PG, Stewart MO, Taylor A, Howell RIS, Lind T Insulin-like growth factor- 1 and its binding protein-1 dur- ing normal and diabetic pregnancies. Obstet Gynecol 1990;76:223-9.

11 Larsen T, Main K, Andersson AM, Juul A, Greisen G, Skakkebaek NE. Growth hormone, insulin-like growth factor 1 and its binding proteins 1 and 3 in last trimester intrauterine growth retardation with increased pulsatility index in the umbilical artery. Clin Endocrinol 1996;45:3159 .

12 Langford K, Blum W, Nicolaides K, Jones J, McGregor A, Miell J. The pathophysiology of the insulin-like growth factor axis in fetal growth failure: a basis for programmin by undernutrition. Eur F Clin Invest 1994;24:851-6.

13 Lewitt MS, Denyer GS, Cooney GJ, Baxter RC. Insulin-like growth factor-binding protein-1 modulates blood glucose growth factor-binding protein-1 modul
levels. Endocrinology 1991;129:2254-6.

14 Holly JMP, Biddlecombe RA, Dunger DB, et al. Circadian variation of $\mathrm{GH}$-independent IGF-binding protein in diabetes mellitus and its relationship to insulin. A new role for insulin? Clin Endocrinol 1988;29:667-75.

15 Rossner S, Ohlin A. Maternal body weight and relation to birthweight. Acta Obstet Gynecol Scand 1990;68:475-8.

16 Harding S, Kyei Mensah A, Hills F, Howell RJS, Chard T. Lack of evidence for a circadian rhythm of IGF binding protein-1 in the mother and fetus during labour. $\mathrm{Br} F$ Obstet Gynaecol 1995;102:891-3.

17 Neilson JP, Alfirevic Z. Doppler ultrasound in high risk pregnancies. In; Neilson JP, Crowther CA, Hodnett ED, pregnancies. In; Neilson J, eds. Pregnancy and Childbirth Module of the Cochrane Database of Systematic Reviews. Oxford: The Cochrane Collaboration, 1997: Issue 1.

18 Soothill PW, Ajayi RA, Campbell S, Nicolaides KH. Prediction of morbidity in small and normally grown fetuses by fetal heart rate variability, biophysical profile score and umbilical artery Doppler studies. Br $\mathscr{f}$ Obstet Gynaecol 1993;100:742-5.

19 Soothill PW, Bobrow CS, Holmes RP. Small for gestational age is not a diagnosis. Ultrasound Obstet Gynecol 1999;13:225-8

20 Cotterill AM, Holly JMP, Amiel S, Wass JAH. Suppression of endogenous insulin secretion regulates the rapid rise of els following acute hypoglycaemia. Clin Endocrinol 1993;38:633-9.

21 Catalano PM, Drago NM, Amini SB. Maternal carbohydrate metabolism and its relationship to fetal growth and body composition. Am f Obstet Gynecol 1995;172:1464-

22 Morris DV, Falcone T. The relationship between insulin sensitivity and insulin-like growth factor-binding protein-1. Gynecol Endocrinol 1996;10:407-12.

23 Holmes RP, Holly JMP, Soothill PW. A prospective study of maternal serum insulin-like growth factor-I in pregnancies with appropriately grown and growth restricted fetuses. $B r$ f Obstet Gynaecol 1998;105:1273-8.

24 Nicolini U, Hubinont C, Santolaya J, Fisk NM, Rodeck CH. Effects of fetal intravenous glucose challenge in normal and growth retarded fetuses. Horm Metab Res and growth ret

25 Giles WB, Trudinger BJ, Baird PJ. Fetal umbilical artery flow velocity waveforms and placental resistance: pathological correlation. Br $\mathcal{F}$ Obstet Gynaecol 1985;92:31-8.

26 McLellan KC, Hooper SB, Bocking AD, et al. Prolonged hypoxia induced by the reduction of maternal uterine blood flow alters insulin-like growth factor binding protein-1 (IGF binding protein-1) and IGFBP-2 gene expression in the ovine fetus. Endocrinology 1992;131:1619-28.

27 Pekonen F, Suikkari AM, Makinen T, Rutanen E-M. Different insulin-like growth factor binding species in human placenta and decidua. $f$ Clin Endocrinol Metab 1988;67:1250-7.

28 Frost RA, Mazella J, Tseng L. Insulin-like growth factor binding protein-1 inhibits the mitogenic effect of insulinlike growth factors and progestins in human endometrial stroma cells. Biol Reprod 1993;49:104-11.

29 Glaser A, Luthman H, Stern I, Ohlsson R. Spatial distribution of active genes implicated in the regulation of insulinlike growth factor stimulatory loops in human decidual and placental tissue of first-trimester pregnancy. Mol Reprod Dev 1992;33:7-15. 